\title{
'She had just cut/broken off her head': Cutting and breaking verbs in Tzeltal
}

PENELOPE BROWN*

\section{Abstract}

This paper describes the lexical resources for expressing events of cutting and breaking ( $C \& B$ hereafter) in the Mayan language Tzeltal. This notional set of verbs is not a class in any grammatical sense; $C \& B$ verbs are formally undistinguishable from many other transitive state-change verbs. But they nicely reveal the characteristic specificity of Tzeltal verb semantics: $C \& B$ actions are finely differentiated according to the spatial and textural properties of the theme object, with no superordinate term meaning either 'cut in general' or 'break in general'. The paper characterizes the semantics of these verbs and shows that in the great majority of cases it does not predict their argument structure.

Keywords: cut and break; separation events; Tzeltal; lexical semantics; verb semantics; argument structure.

\section{Introduction to the language and speakers}

A favorite bogeyman of Tzeltal Mayan speakers is the folk anti-hero $j$-k'ok-jolol 'severed head': stories about this mythical woman who could remove ( $k$ 'ok 'cut/break off') her head are told to scare children and entertain adults. ${ }^{1}$ It also confronts one nicely with the kinds of semantic distinctions in Tzeltal verbs for cutting and breaking: $k$ 'ok means to 'sever' a body part, but it also means to pick largish fruit from a tree. Apparently the connection is something like: 'detach a part of suitably impressive size/importance from its animate (or plant) whole', not caring whether a sharp instrument (cut) or just hands (break, pick) are used to achieve this. Tzeltal, then, has something to contribute to the large literature on 'verbs of material destruction' (as do other Mayan languages: Pye 1994, 1996). In this paper I describe the lexical resources of Tzeltal for referring to 
events of cutting and breaking (henceforth $\mathrm{C} \& \mathrm{~B}$ verbs), and show that Tzeltal is illuminating for several reasons: (i) the wide variety of roots distinguishing different kinds of $\mathrm{C} \& \mathrm{~B}$ events, (ii) the culture-specific semantic distinctions many of these verbs make, (iii) the absence of any overarching general verbs in this domain, and (iv), the absence of syntactic distinctions that provide a clue to verb semantics.

Tzeltal is a Mayan language spoken by around 220,000 people in Chiapas, Mexico. ${ }^{2}$ They live by farming, the principle crops being corn, beans, squash, fruit, and a cash crop of coffee. Their vocabulary for C\&B events is colored by this ecology, by their agricultural tools (machetes, axes, hoes), and by the fact that they cook and warm themselves solely with wood fires.

The Tzeltal verbal lexicon is characterized by a relatively small number of canonically CVC roots (perhaps 800 ), with a very productive derivational morphology enabling valence and voice changes, nominalization, etc. As in the rest of the verbal lexicon, in the C\&B domain we find Tzeltal speakers are splitters rather than lumpers: ${ }^{3}$ there are many fine discriminations resulting in a total of 54 distinct $\mathrm{C} \& \mathrm{~B}$ verb roots in my dictionary. Note, however, that $C \& B$ verbs are formally undistinguishable from many other transitive verbs expressing change of state, for example, 'bend without breaking', 'open', 'extract from tight fit'. The meanings of some C\&B verbs overlap with those of verbs of separation (e.g. jat' 'break plant off at base or pull it up by the roots') or opening (e.g., jaw as a positional means 'lying face up', but as a transitive verb could mean 'separate/cut so that two halves fall apart face up').

The data for this study are of three kinds: (i) responses to the Cut and Break stimulus set of videoclips (Bohnemeyer et al. 2001; see introduction, Majid et al., this issue, for description of clips), carried out with three consultants (two female, one male), (ii) lexical entries in my Tzeltal field dictionary, and (iii) elicitation with several consultants about the argument structure properties of the $\mathrm{C} \& \mathrm{~B}$ verb roots.

\section{Semantics in the domain of cutting and breaking}

There is no overarching superordinate term meaning either cut in general or break in general in Tzeltal. Cutting and breaking actions are finely differentiated and are not hierarchically arranged-Tzeltal speakers insist that one is not a subtype of another. A few are near-synonyms (e.g., the two tearing verbs $c h^{\prime} i$ ' and jatz), but the majority apply to finely discriminated sets of event types. Tzeltal provided the largest number of verbs in response to the $\mathrm{C} \& \mathrm{~B}$ stimulus set of all the 28 languages sampled. The 54 $\mathrm{C} \& \mathrm{~B}$ verbs in my corpus are listed in Tables $1-3$ in the Appendix, 
with glosses indicating prototypical theme objects they are associated with. ${ }^{4}$

The most important semantic features C\&B verbs lexicalize are the following:

(i) properties of the theme object: e.g. long thin hard (stick/nail: $k^{\prime} a s$ ); flexible (rope/cloth/leaf/paper: ch $^{\prime}{ }^{\prime}$ ); round and hard (head/pot: woch'); 3D soft vs. brittle (sew vs. top'); small vs. large object (xet' vs. xet); multiple-stranded object (hair/grass/cornsilk: jax).

(ii) spatial properties of the action in relation to the theme's axes or parts, e.g. across/along the long axis (set' vs. sil or jep); part/whole relation (k'ok, ch'uy).

(iii) result: e.g., completion of resulting $C \& B$ effect on the theme entailed ( $t z^{\prime} e t$, mak', tuch') or not (boj, jatz, p'ij); create a break in brittle object (xet) vs. shatter it completely (top') vs. break into its inside (woch'); make one cut or more than one (tzep, p'ij vs. sil); small vs. large pieces ( $t$ 'ol vs. jis).

Less widely applicable, but distinguishing some of the C\&B verbs, we find:

(iv) manner: e.g., sharp blow (boj) vs. sawing action (tuy); sudden split (jatz, tuch') vs. incremental split/tear (ch'i').

(v) type of instrument: relevant for just a few verbs: e.g., sharp blade (set'), hands (xet').

While Mayan languages in general make similar distinctions (Pye 1996), they do not always agree about which are the most important for the C\&B domain; for example, in Yukatek Maya instrument is one of the most important semantic distinctions (Bohnemeyer and Brown 2007).

Other distinctions can be optionally encoded outside the verb root (in the examples, boldface marks the C\&B root): ${ }^{5}$

Instrument, with a prepositional phrase:

(1) ya j-ch'i'-ø pak' ta j-k'ab. ICP 1E-rip-3A cloth PREP 1E-hand 'I rip the cloth with my hands.'

or with a passive:

(2) jes-ot kuchilu. slice-PASS knife

'(It) was sliced (by) a knife.'

Manner, with an iterative derivation: -tikla 'do action repeatedly': 
(3) ya s-set'-tikla- $\varnothing$ sanoria.

ICP 3E-cut-ITER-3A carrot

'She repeatedly slices the carrot (across the long axis).'

or with reduplication:

(4) tzep-tzep-ta-bil.

cut.surface-REDUP-REP-PPT

'It has been repeatedly cut/sliced into.'

or with other morphosyntactic devices (e.g. adverbs, prepositional phrases).

For many C\&B verbs, completion of cutting/breaking as a result is not entailed. You can, for example, say (as one consultant did in response to a stimulus showing an agent sawing at a branch with a hatchet till it finally breaks off the tree):
ya s-tuy- $\varnothing \quad$ ta eche' te',
peru ma ba $\varnothing \quad$ tuy- $\varnothing$.
ICP 3E-cut-3A PREP axe branch, but NEG CMP cut-3A
'He was cutting the branch with an axe, but it didn't cut.' (Instead, it just broke off).

You can, however, explicitly express the completed result of the C\&B action with a directional adverb:
(6)
$\begin{array}{llll}\varnothing & \boldsymbol{k} \text { 'ok- } \varnothing & \text { bel } & s \text {-jol. } \\ \text { CMP } & \text { cut/break-3A } & \text { awaywards } & \text { 3E-head }\end{array}$
'Her head cut/broke off.' (our cut/broken-headed demon)

These locutions can make a cut/break predication out of non-C\&B roots (e.g., 'squash it in half', 'pinch it off').

Some Tzeltal verbs make crosslinguistically familiar semantic distinctions and apply to a wide range of situations. For example, the verb boj 'cut/break with a sharp blow or bladed instrument' was used by at least one consultant to describe 24 stimulus scenes which involved a sharp blow with a bladed instrument or a hand karate chop, resulting in a cut or break in an object regardless of its spatial and textural properties (e.g., branch, cloth, carrot, rope, melon, finger, fish). For three of these scenes (cut branch/cloth/finger with knife), all three consultants gave boj as their first response, indicating perhaps some prototypicality of those scenes for this verb. Yet there was considerable inter-speaker variability: for 8 scenes boj was only one of several verbs used and the three consultants each gave a different verb as their first response. And boj is not a superordinate cut verb, being inapplicable to more than half the stimulus scenes. Other uses of boj indicate that completion of cutting/separation is not entailed by this verb. 
In contrast to $b o j$, the verb tuch' 'suddenly break/split long/flat/flexible object', which was applied to 18 of the stimulus scenes, is a relatively Tzeltal-specific category, covering some classic cutting events (e.g., cut rope with scissors/knife) and some breaking ones (e.g., break cloth with sudden karate chop, break wool by pulling it apart with hands, rope spontaneously breaks in two). Tuch' requires an object like cloth, paper, leaves, rope, or stick which can break across its fibers; it also attends to a property of the material - increasing thinness - as stress is being put on it to tear/break it. It is indifferent to the tool used to achieve the result or in what manner the action is done, but the cut/split must be sudden (like the English verb snap).

For many of the stimulus scenes, speakers are willing to use more than one verb, depending on what perspective they take on the scene (e.g., focus on instrument vs. result), but they do not always agree about the range of contexts a verb extends to.

\section{Argument structure}

Comparative work on C\&B verbs (e.g., Guerssel et al. 1985) has argued for a basic split between two types of verbs with distinct event structures: cut verbs specify a particular causing event, but break verbs do not, focusing instead on the end result of a cut/break action. Their argument structures contrast accordingly. Two-argument cut verbs, which predicate an agent acting on a theme and focus on instrument/manner, are incompatible with the causative/inchoative alternation but take the conative alternation, whereas single-argument break verbs, which predicate a theme breaking, focusing on the resulting state, are compatible with a transitive/ inchoative alternation but do not take the conative.

Since Tzeltal is a free-argument-ellipsis language, we cannot rely on overt presence of arguments to assess verbs' argument structure. Establishing whether the verbs' semantics predicts their argument structure involves assessing each verb's ability to take the different valence-changing morphology the language provides. There are two Tzeltal valencechanging operations that seem comparable to the transitive/inchoative (demoting the agent) and the conative (demoting the undergoer). Tzeltal $\mathrm{C} \& \mathrm{~B}$ verbs fall into one of three classes on the basis of their ability to undergo these operations (see Tables 1-3, in the Appendix).

All Tzeltal verbs reliably distinguish intransitive and transitive forms; these have distinct aspect paradigms and in addition, transitives are obligatorily marked with ergative cross-referencing of the agent. Many roots are base transitive and have to be derived in order to be used intransi- 
tively; others are intransitive and have to be causativized in order to be used transitively. Many Tzeltal verbs - including almost all the C\&B roots - can be used either way with the very productive mediopassive derivation, ${ }^{6}$ in the transitive/intransitive alternation.

Test 1: mediopassive derivation
a. transitive:
ya $\quad \mathbf{j}-\boldsymbol{b o j}-\varnothing$
te'.
INC 1E-cut.sharp.blow-3A stick/wood
'I cut the stick/wood.'
b. intransitive: $y a$-boj- $\varnothing \quad k$-u'un.
ICP ASP-cut.sharp.blow3A 1E-RelN
'It cuts by/because of me.' (i.e., I can cut it).
(8) a. transitive: la s-xet- $\varnothing$ ti' p'in.
CMP 3E-chip-3A lip pot
'She chipped (the) pot's lip.'
b. intransitive: $\boldsymbol{x} \boldsymbol{e}$-j-t-em-ix p'in.
chip-PERF-ACS pot
'The pot has chipped (large bit broken off at lip).'

This mediopassive preserves the undergoer (U) argument, although the agent (A) can be (re)introduced by adding a relational noun meaning 'by/because of I/you/him' etc. (as in 7b). Judging by this test - an alternation preserving the $\mathrm{U}$-argument, which almost all the $\mathrm{C} \& \mathrm{~B}$ verbs in my corpus can take - these verbs are U-centered, break-type verbs.

A second way to make a transitive verb intransitive highlights the importance of the A-argument. The antipassive demotes the object, and expresses only the agent or instrument, often with a generic reading as in:

Test 2: antipassive derivation.

(9) ya x-laktz'un-wan kawayu

ICP ASP-break.through.(fence)-ANTIPASS horse

'horses break through [fences]' (habitually)

(10) ya x-tuy-awan j-k'ab-tik

ICP ASP-cut-ANTIPASS 1E-hand-1PLincl

'our hands (are used to) cut (things)'

(11) ya x-t'oj-awan mut.

ICP ASP-drill-ANTIPASS bird

'The bird [woodpecker] drills (something).' (characteristically).

Roots which take this antipassive have a focus on the A-argument.

Table 1 in the Appendix lists all the C\&B verbs that pass both of these tests. These verbs are therefore members of what I will call Class 1: both 
A-centered and U-centered verbs (or neutral as to A- vs. U-centering), construable either way. This accounts for the majority of $C \& B$ verbs in the language, regardless of whether their semantics is cut-like (predicating an instrument/manner) or break-like (predicating a state change).

Just two C\&B verbs pass Test 2 but do not take the mediopassive; these are Class 2 verbs (see Table 2, Appendix): $t$ 'oj 'strike/cut wood with axe or stick, not necessarily cutting through it' and kitz 'scratch with knife, not necessarily fully cut through'. Both these verbs require an instrument argument.

A third class of verbs, whose underived form is an intransitive root, take the intransitive aspect set without derivation, but require a causative suffix to indicate a causer (Table 3, in the Appendix). Only two C\&B roots (sok 'break mechanically' and t'om 'explode/blow up/pop') are base intransitive according to these tests. For example, sok 'break mechanically' (i.e., cease to function), must be causativized as sok-es to mean 'make something break mechanically'. Root intransitives do not take the antipassive: you can't say *ya $x$-sok-awan 'it mechanically breaks' (because 'there's no one doing the sok-ing', no agent). ${ }^{7}$

So does Tzeltal have two kinds of $\mathrm{C} \& \mathrm{~B}$ verbs, cut verbs vs break verbs? Is the mediopassive-creating a transitive/intransitive alternation - an adequate test of whether Tzeltal has two kinds of C\&B verbs? First we must establish whether this Tzeltal mediopassive is interpreted as inchoative (no A-argument) or as middle voice (with A suppressed but still understood). Bohnemeyer (this issue) argues that, insofar as the mediopassive is a voice alternation, it should be applicable to both cuttype and break-type verbs but with different interpretations in the two sets. Break verbs should occur with passive, middle (in the sense of ' $\mathrm{X}$ is easy to V') and inchoative interpretations in the mediopassive, but cut verbs should occur only with passive and middle, but not with inchoative senses.

The evidence in Tzeltal is equivocal; consultants accept a number of cut verbs with inchoative senses in the mediopassive. Example (7b) might suggest a middle interpretation with A being suppressed, since an A can be (re)introduced by a relational noun. However the same construction can occur with a patently intransitive verb like 'cry' (e.g., ok' ku'un 'she cried because of me'). The mediopassive can definitely describe tensed events (e.g. ya xset' ya'tik 'it cuts/is cutting right now'), with an inchoative interpretation, as well as being open to a generic interpretation (e.g., wokol ya xsejt te te'e 'the tree cuts with difficulty'). And verbs used to describe the four spontaneously-caused scenes of the C\&B stimulus set, where the event just happened with no instrument or causer visibly acting, were invariably drawn from the same set as the caused scenes, but 
now used in the mediopassive, often with the reflexive 'by itself', indicating that there was no agent involved:

(12) (stimulus: a branch, or a carrot, breaking spontaneously)

$\varnothing \quad \boldsymbol{k}$ 'as- $\varnothing \quad s$-ba $\quad$ s-tukel.

CMP break-3A 3E-self 3E-alone

'It broke in two by itself.'

A cut verb can also be used in this construction:
ya $\quad x$-majk'- $\varnothing$ s-tukel.
ICP ASP-cut.into.chunks-3A 3E-self
'It cuts (into chunks) by itself.'

Since verbs with the semantics of both cut and break fall together in Class 1, compatible both with the U-centered mediopassive - in both generic and inchoative senses - and with the A-centered antipassive, does this mean that all Tzeltal $\mathrm{C} \& \mathrm{~B}$ verbs are break verbs, with no causal event lexically specified? I think that the semantics of some of these verbs is transparently cut-like, specifying an instrument or manner (e.g., mak', set', tuy). Further, the distinction between these Class 1 verbs and the clearly two-argument Class 2 verbs, which don't take the mediopassive, in contrast to Class 3 verbs which require causativization to be used transitively, argues against the interpretation that all Tzeltal $\mathrm{C} \& \mathrm{~B}$ verbs have break semantics.

\section{Conclusion}

Tzeltal proliferates micro-distinctions for $\mathrm{C} \& \mathrm{~B}$ verbs, especially surrounding culturally schematized activities like cultivating corn, preparing food, building wooden houses, collecting firewood. When a language divides the $\mathrm{C} \& \mathrm{~B}$ domain up so finely, not much can be concluded about the universal dimensions underlying the distinctions the verbs make. It does seem that Tzeltal verbs lexicalize some of the same object properties as do $\mathrm{C} \& \mathrm{~B}$ verbs in other languages - long thin vs. round, hard (shatterable) vs. soft (sliceable), fibrous (cloth, rope) vs. homogeneous (watermelon), two-dimensional (cloth, paper) vs. three-dimensional, the cut or break occurring across vs. parallel to the long axis. Yet many other more culturespecific properties are important for Tzeltal verbs in this domain (e.g., being applicable only to one kind of theme object, like $k^{\prime} a j$ 'break off mature corn from plant' or t'ox 'split wood down middle along long axis'). The wide variety of semantically specific verbs available means that speakers often have several options for how to express a given $\mathrm{C} \& \mathrm{~B}$ event depending on the perspective they take, e.g., whether they focussing on 
manner or on result. This is reflected in the large amount of interspeaker variation in responses to the $\mathrm{C} \& \mathrm{~B}$ stimulus set.

Although Tzeltal has a wide array of verbs for cutting and breaking, the semantics of the great majority of these $C \& B$ verbs does not appear to predict their argument structure, as Pye (1996) found also for C\&B verbs in K'iche' Maya. Almost all the roots can be readily construed either transitively or intransitively, regardless of whether they entail an instrument or not, an agent or not. In Tzeltal there is no clear syntactic division into verbs of cutting (which focus on what the agent does and with what instrument/manner) vs. breaking (which focus on the result to the undergoer); morphological processes allow a verb to be construed from either perspective. Further work is needed to determine to what extent and in what ways the antipassive and mediopassive constructions have both argument-structure changing and voice functions, but on current evidence it seems that Tzeltal C\&B verbs demonstrate the limitations of inferring argument structure from lexical semantics, since generalizations about argument structure for these verbs do not hold at the root level, but only for the derived stem - they come from the abstract semantics of the transitivizing and intransitivizing derivations.

Received 1 December 2004

Revision received 25 June 2006
Max Planck Institute for Psycholinguistics, Nijmegen, The Netherlands

\section{Appendix}

Table 1. Tzeltal verbs of cutting and breaking ${ }^{8}$ _Class 1: Both A- and U-centered verbs (or neutral as to A-vs. U-centering)

\begin{tabular}{|c|c|}
\hline $\begin{array}{l}\text { Verb } \\
\text { root }^{9}\end{array}$ & Gloss \\
\hline bis & 'cut surface deep enough to make a visible scratch' \\
\hline boj & 'cut with sharp blow across the long axis' (tree, weeds, body, fruit, thick things) \\
\hline ch'i' & $\begin{array}{l}\text { 'break, tear, split incrementally' (cloth, paper, leaf, any flexible plane, but not } \\
\text { skin on body) }\end{array}$ \\
\hline ch'ul & 'shave off small bits, plane surface' (wood) \\
\hline ch'uy & 'cut part from whole' (bananas from stalk, limb of tree from the tree) \\
\hline jat & $\begin{array}{l}\text { 'make major cut or split', e.g. in belly (for operation), or in earth (in an } \\
\text { earthquake) }\end{array}$ \\
\hline jat' & 'break plant at base, or pull up by roots, or split' (lip, skin) \\
\hline jatz & 'tear suddenly' (cloth, paper, leaf) \\
\hline jaw & 'cut/break so that it falls open in two halves; open' (mouth, scissors) \\
\hline jek & 'break off at base' (e.g. banana from bunch, tree branch) \\
\hline jep & 'split in vertical halves' (fruit or vegetable) \\
\hline jes & 'slice off thin slice from' (meat, apple) \\
\hline
\end{tabular}


Table 1 (Continued)

\begin{tabular}{|c|c|}
\hline $\begin{array}{l}\text { Verb } \\
\text { root }^{9}\end{array}$ & Gloss \\
\hline jis & $\begin{array}{l}\text { 'cut into planks/slice into strips back and forth along long axis' (meat, banana } \\
\text { leaves, cloth) }\end{array}$ \\
\hline jos & 'cut off little bits' (to make a point or to remove skin) \\
\hline jotz & 'cut/break weeds' (with hand or hoe) \\
\hline jox & 'peel, skin, shave, cut' (hair, sheep's wool, grass, cornsilk) \\
\hline jut & 'pierce' (with sharp implement) \\
\hline$k^{\prime} a j$ & 'break off, mature corn from plants' (only corn) \\
\hline$k^{\prime} a l$ & 'break into pieces lengthwise with the grain' (big things: firewood, shingles, tiles) \\
\hline k'as & $\begin{array}{l}\text { 'break in two pieces, roughly in half' (non-flexible long object like stick, nail, } \\
\text { tile, cornstalk or tree blown down by wind) }\end{array}$ \\
\hline k'ok & 'sever body part' (e.g. head, finger, foot); 'pick fruit from branch'. \\
\hline$k^{\prime} u t$ & $\begin{array}{l}\text { 'break/separate with twisting motion' (shell corn; break in half a bunch of } \\
\text { greens) }\end{array}$ \\
\hline k'um & 'partially break and bend over tops of corn plants, leaving on plant to dry' \\
\hline laktz'un & 'break through a barrier' (e.g. fence) \\
\hline$m a k^{\prime}$ & 'cut/slice hard object crosswise into chunks' (e.g. firewood) \\
\hline$p^{\prime} \ddot{i j}$ & $\begin{array}{l}\text { 'break long thin thing in two' (e.g. stick, anything that takes strength to break) } \\
\text { (more or less }=k^{\prime} a s \text { ) }\end{array}$ \\
\hline poch' & 'cut or pull' (peel off fruit); 'skin' (animal) \\
\hline putz' & 'partially break long thing, result is not fully broken' \\
\hline set' & $\begin{array}{l}\text { 'cut across long or thin object' with sharp tool (paper, rope, flowers, cloth, cable, } \\
\text { but not bread); 'cut around outside of object' (e.g. ringing a tree) }\end{array}$ \\
\hline sew & $\begin{array}{l}\text { 'cut round or bulky soft thing across long axis' (bread, onion, fruit, but not } \\
\text { cloth) }\end{array}$ \\
\hline sil & 'cut into slivers, slice along long axis' (firewood, carrot, green beans) \\
\hline toch' & 'peel off, rip/break/detach surface' \\
\hline top' & $\begin{array}{l}\text { 'cut/break brittle things' (firewood, wooden house, tiles, pot, gourd bowl, dish, } \\
\text { mirror, guitar) }\end{array}$ \\
\hline tuch' & 'cut, break in two across fibers, suddenly' (rope, cable, string, hair, sewn seam) \\
\hline tuy & 'cut flexible thing with sharp instrument' (paper, meat, cloth, twig) \\
\hline t'il & $\begin{array}{l}\text { 'break into pieces' (bricks, crockery, tiles, mirror); 'chip small bit(s) off' (pot's } \\
\text { lip) }\end{array}$ \\
\hline t'ol & 'cut/break into big chunks' (meat, firewood, stones) \\
\hline t'ox & 'split wood down the middle along long axis with axe' \\
\hline$t^{\prime} u s$ & 'break/squash between fingers' (fruit/eggs/bugs) \\
\hline tzep & 'slice once into with machete or other sharp instrument' (e.g. tabletop, wood) \\
\hline$t z^{\prime} e t$ & 'cut down at base' (tree, big strong weeds) \\
\hline$t z^{\prime} a p$ & 'pierce, stab one end of long thing into surface' \\
\hline$t z^{\prime} u p$ & 'pierce, stab point of sharp thing into surface' \\
\hline wis & 'scrape, cut by sawing motion' (e.g. cord, wire); 'open/shut a zipper' \\
\hline woch' & 'break into inside of' (box, carton, pot, computer) \\
\hline wuch & 'break, smash, destroy' (tortilla, egg, pail, house, car) \\
\hline wuy & 'break brittle thing into pieces' (cement, pottery, glass) \\
\hline xet & $\begin{array}{l}\text { 'tear fragments of thin pliable things larger than } x e t \text { ' (e.g. blanket); 'cut/break a } \\
\text { pot into large pieces' }\end{array}$ \\
\hline$x e t^{\prime}$ & 'break flexible thing' (paper, tortilla, bread, leaves) \\
\hline$x o t$ & $\begin{array}{l}\text { 'cut/break large thing across long axis into two, with machete or axe' (wood, } \\
\text { fish) }\end{array}$ \\
\hline
\end{tabular}


Table 2. Tzeltal verbs of cutting and breaking_Class 2: A-centered (transitive) only, don't take mediopassive

\begin{tabular}{ll}
\hline Verb root & Gloss \\
\hline$t^{\prime} o j$ & 'strike/cut wood with axe or stick, not necessarily cutting through it' \\
$\boldsymbol{k i t} z$ & 'scratch with knife, not necessarily fully cut through' \\
\hline
\end{tabular}

Table 3. Tzeltal verbs of cutting and breaking_Class 3: U-centered only (intransitive, not transitive unless causativized with -es)

\begin{tabular}{ll}
\hline Verb root & Gloss \\
\hline sok & 'break, malfunction' (e.g. machine, head, computer, car) \\
t'om & 'explode, pop' (e.g. firecracker, balloon, tree blown down by big wind) \\
\hline
\end{tabular}

\section{Notes}

* Contact details: Penelope Brown, Max Planck Institute for Psycholinguistics, Postbus 310, 6500AH Nijmegen, The Netherlands; Email: 〈Penelope.Brown@mpi.nl.〉

1. See Stross (1978) for a version of the story. I have also heard modern versions (in the late 1990s) taken to be real news!

2. This study is based on data collected in the municipio of Tenejapa, a rural area where many monolingual speakers still thrive, although the younger generation is increasingly becoming bilingual in Spanish.

3. See Brown $(1994,2006)$, for specificity in Tzeltal lexical semantics.

4. The multiplicity of semantic features distinguishing these verbs means that their glosses here are truncated and inadequate.

5. The following abbreviations are used in Tzeltal glosses: ICP-incompletive; CMP-completive; E-ergative; A-absolutive; ITER-iterative; NEG-negation; PASS-passive; PERF-perfective; PPt—passive participle; PREP-preposition; REDUP-reduplication; RelN—relational noun; REP—repeated action; STAT—-stative.

6. The mediopassive derivational infix is minimal; it is a productive derivation making a transitive root into an intransitive stem, often with no morphological marking, e.g., $t^{\prime} o x$ 'to split wood' $\rightarrow$ t'ox 'to be split' (of wood). CVC roots with a specific phonetic shape take an infixed $-j-[\mathrm{h}]$ in the intransitive form: the root's second consonant must be a stop or affricate ( $p, t, t s, c h, k$, or the corresponding glottalized forms); otherwise the mediopassive form is identical to the transitive root (Kaufman 1971: 54).

7. One other derivation — with a $-\mathrm{Vl}$ suffix — produces a stem that predicates a state, e.g., a position ('sitting') or condition ('old, worn out'). Most C\&B verbs (all but 5 of those in Table 1) do NOT take this stative ending; they resist being construed solely as in a stateof-being-cut/broken. The ability to take this stative derivation suggests a focus on the $\mathrm{U}$ and what happened to it.

8. With one exception, Table 1 includes only roots, not derived stems or compounds combining two C\&B roots (e.g. jek-ch'uy "lit: 'break-off-at-base' + 'cut off from stalk or trunk', meaning 'cut pieces of body off at joints"'). The one exception is the verb stem lak-tz'un, which is derived from a Positional root-lak- (cf. endnote 6). Also, I have not included verb roots - even if they were used in responses to the C\&B stimulus set-that do not have construably $\mathrm{C} \& \mathrm{~B}$ semantics. These include non- $\mathrm{C} \& \mathrm{~B}$ verbs of separation, 
e.g. 'twist (off)' ( $t z^{\prime} \circ t$ ), 'pinch (off)' (xut'), 'pull weeds out' ( jotz), 'divide into shares' (e.g., land, xat', food ( pew), 'open' ( jam, kay), nor verbs which do not entail a (at least partially) surface-integrity cut/broken result, e.g. 'bend without breaking' ( juy), 'squash' (ten)). Note, however, that these verbs display the same Class 1 argument structure patterns as the $\mathrm{C} \& \mathrm{~B}$ verbs listed in Table 1 .

9. Boldface indicates verbs used in responses to $\mathrm{C} \& \mathrm{~B}$ stimulus set.

\section{References}

Bohnemeyer, Jürgen

this issue Morpholexical relatedness and the argument structure of verbs of cutting and breaking. Cognitive Linguistics 18(2), 153-177.

Bohnemeyer, Jürgen, Melissa Bowerman, and Penelope Brown

2001 Cut and break clips. In Levinson, Stephen C., and N. J. Enfield (eds.), Field Manual 2001, Language and Cognition Group, Max Planck Institute for Psycholinguistics. Nijmegen: MPI, 90-96.

Bohnemeyer, Jürgen, and Penelope Brown

2007 Standing divided: Dispositional verbs and locative predications in two Mayan languages. In Ameka, Felix K., and Stephen C. Levinson (eds.), special edition of Linguistics 45(5/6), 1105-1151.

Brown, Penelope

1994 The INs and ONs of Tzeltal locative expressions: The semantics of static descriptions of location. Linguistics 32, 743-790.

2006 A sketch of Tzeltal spatial language. In Levinson, Stephen C., and David Wilkins (eds.), The Grammar of Space. Cambridge: Cambridge University Press, 230-272.

Guerssel, Mohamed, Kenneth Hale, Mary Laughren, Beth Levin, and Josie White Eagle 1985 A crosslinguistic study of transitivity alternations. In Eilfort, William H., Paul D. Kroeber, and Karen L. Peterson (eds.), Papers from the Parasession on Causatives and Agentivity at the 21st Regional Meeting. Chicago: Chicago Linguistic Society, 48-63.

Kaufman, Terrence

1971 Tzeltal Phonology and Morphology. Berkeley, CA: University of California Press.

Majid, Asifa, Melissa Bowerman, Miriam Van Staden, and James S. Boster

this issue The semantic categories of cutting and breaking events: A crosslinguistic perspective. Cognitive Linguistics 18(2), 133-152.

Pye, Clifton

1994 Breaking concepts: Constraining predicate argument structure. Unpublished manuscript. Department of Linguistics, University of Kansas.

1996 K'iche' Maya verbs of breaking and cutting. Kansas Working Papers in Linguistics 21. Lawrence, KS: University of Kansas, 87-98.

Stross, Brian

1978 Tzeltal tales of demons and monsters. Museum Brief 24. Columbia MO:

University of Missouri-Columbia. 